\title{
SOME OBSERVATIONS ON THE HANDSHAKE AS A CRUCIAL INDICATOR OF THE EMPATHIC AND PEACEBUILDING CULTURE
}

\author{
JOANNA PUPPEL
}

\begin{abstract}
Handshake is a very primeval human gesture which follows from the erect posture and the freeing of the upper limbs. Its evolutionary benefits for mankind are briefly discussed. It is emphasized that the free hands, the right hand in particular, have been of fundamental importance to human culture thus underlying interpersonal linkages and communication. Handshake is loaded semantically positively and in this capacity it serves in a number of important integrative functions in human social life, in particular, in peacebuilding.
\end{abstract}

Key words: free upper limbs, handshake, palm grip, right handedness, body perimeter, empathy, peacebuilding

Let us make a handshake between us (anonymous)

\section{The origins of handshake}

Handshake is regarded as one of the most common and most taken-for-granted gestures ever used by members of the human species while meeting each other. It is easily recognized in all the local cultures across the globe and, as such, it does not require any special training to be introduced in interpersonal contacts. The presence and persistence of the handshake in human history may be derived directly from our erect posture and the freeing of the upper limbs. The free upper limbs, known as the 
'hands' (cf. Brown, 1991, where the hand is listed as one of the human universals), have ever since been involved in countless many manifestations of human culture. In fact, the free hands are not only a miracle of biomechanics but they are also a major symptom of humanness which may simply be defined as being co-determined by various hand activities. In very general terms, the hand system does belong to the biology and sociology of the body (cf. Turner, 1984; Synnott, 1993). Supported by the human ocular dimension, the hands-eyes complex, which is referred to as the 'visual-tactile modality' constitutes the basis of the human communicative potential together with the 'auditory-vocal modality'. According to Merriam Webster's Learner's Dictionary, handshake is the act of grasping someone's right hand with your right hand and moving it up and down. It follows from this definition that it is the right hands during an encounter which are involved in a palm grip which may be either soft or firm, but neither too soft nor too firm (this is the question of the completeness of grip).

The reason for this particular exercise of right handedness (or hand preference, see e.g. Alpenfels, 1955; Cashmore et al., 2008; Cochel and Byrne, 2013, to cite only a small fraction of literature on the subject of human handedness) lies deep in the evolution of the human posture and gait (bipedalism) and in a number of advantages which the human species has generally gained by assuming the erect posture (cf. Wilson, 1998; Rolian et al., 2010). Among the various benefits of the upright posture, the following have been widely recognized by anthropologists: a smaller amount of energy expenditure connected with bipedal gait, more comfortable food transport over longer distances, safer transport of babies (infant carrying), tool-making, feeding/feasting adaptations, better care of offspring in camping sites, better defense against predators (e.g. throwing stones and other projectiles), better access to natural resources (i.e. better food-gathering, e.g. gathering berries, digging tubers, killing game), building shelters, and making fires (cf. Hewes, 1961; Marzke, 1999; Niemitz, 2010).

In addition, all these factors must be supplemented by the fact that the free hands have in the long run allowed the humans to undergo an extremely important cultural adaptation, that is, it has involved the human kind in a number of manual manipulations of a communicative nature, in particular, in developing an efficient non-verbal communication system which has so successfully supplemented the oral communication system. But, above all, the free hands (especially the right hand preference referred to as 'dextrality') have made it possible for humans to develop and perform an important hand-touching and culture-determined (ritual) gesture, the handshake, in the procedure of a human-to-human encounter. Its presence has been attested very early in human history which is shown in some ancient reliefs which humanity has been lucky to preserve to the present times. Most notably, one of the best known handshakes can be seen on a relief dating back to the fifth century BC where Hera (patron-deity of Samos) is seen clasping hands with Athena (patrondeity of Athens). The relief is shown below (Fig. 1) 


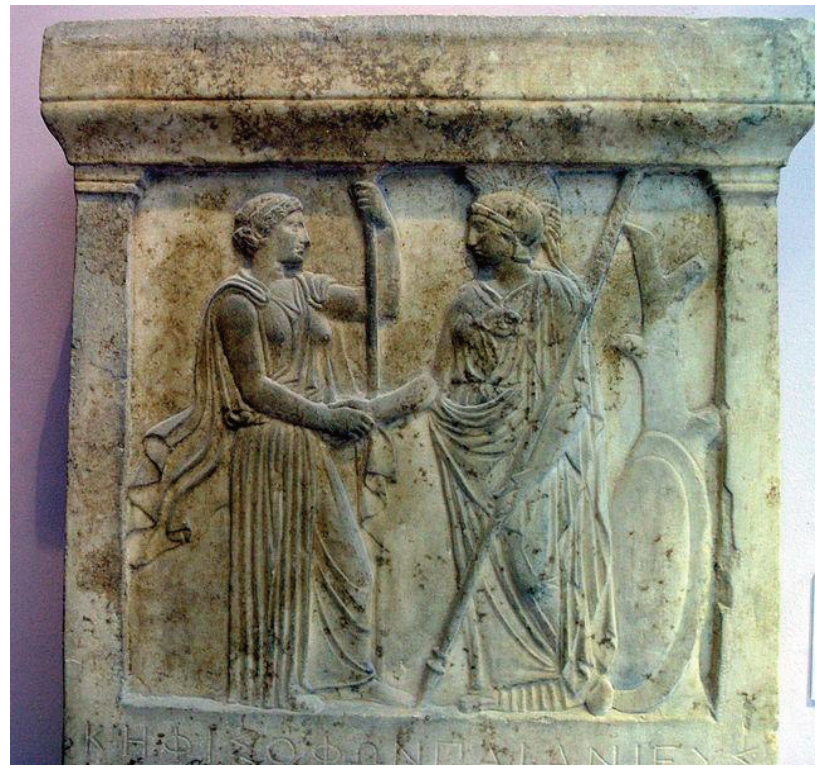

Fig. 1. Hera and Athena clasping hands on a relief inscribed stele (on collection in the Acropolis Museum in Athens, Greece. (Source: https://commons.wikimedia.org/wiki/category:ancient_Samos).

\section{Another ancient relief shows a handshake at a funeral scene (Fig. 2)}

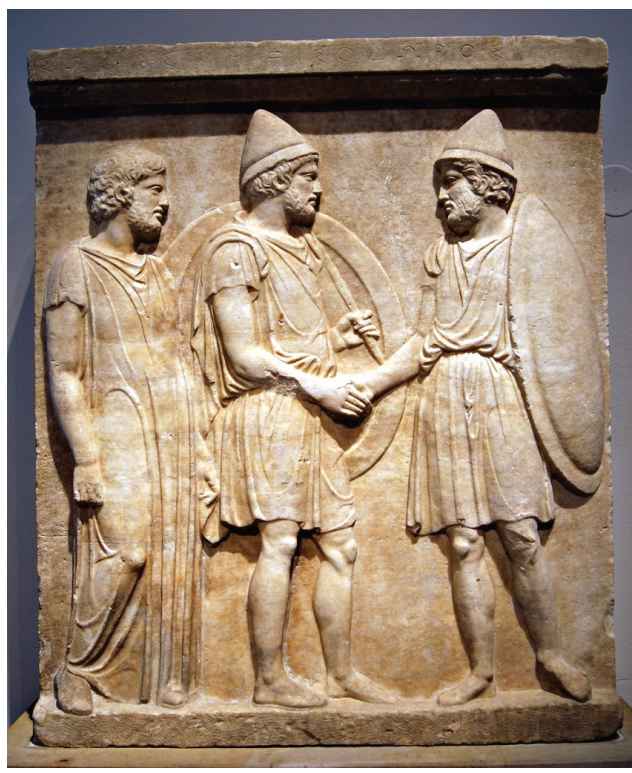

Fig. 2. A funeral relief of Sosias and Kephisodoros (on display in the Altes Museum in Berlin, source: www.flickr.com/photos/magika2000/6853148809/). 
It is interesting to note in connection with those ancient manifestations of handshake that no real handshake has been attested in visual materials from ancient Egypt, though one may find a handshake carved on a relief found on the throne pedestal of the Assyrian king Shalmaneser III (ruling in the years 859-827 BC). This relief is shown below (Fig. 3).

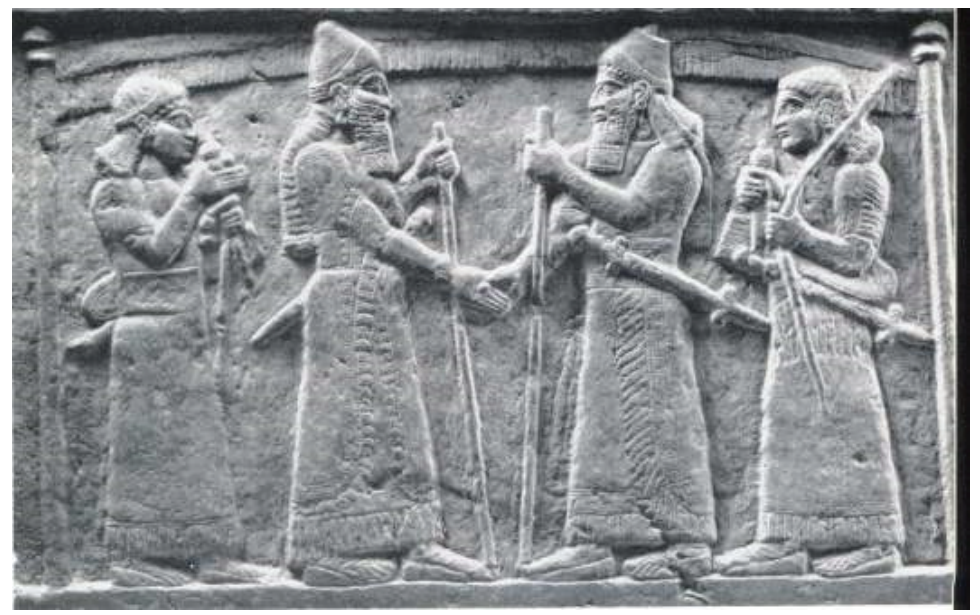

Fig. 3. The Assyrian king Shalmaneser III is shaking hands with a Babylonian king while sealing a peace treaty with Babylonia. (Source: https://factsc.com/history-behing-handshake/).

\section{The handshake as an operation of the body perimeter frontal enlargement}

Topologically, the handshake is a right hand-protruding operation during which the trunk of the human body is simply enlarged frontally (the so-called sagittal/anterior view, see e.g. Bergstrand, 2018) in order to allow an inter-body contact by means of palm touching and grasping, among other manual manipulations, with minimum personal distance (see Fig. 4 below).

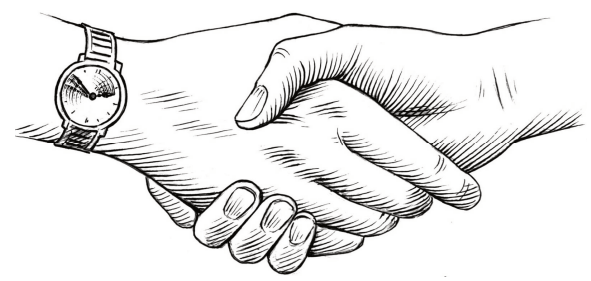

Fig. 4. The handshake as an example of a right hand-protruding operation during which the perimeter of the human body is frontally enlarged. (Source: www.bronislavmarketing.cz/budeme-si-spolu-rozumet/ handshakes-05-gq_31Oct13_b_1445x878/). 
The handshake is a perfect example of such an enlarging operation of the perimeter of the trunk-integrated human posture, as shown in the figure below (Fig. 5) which represents the so-called 'posture at attention'.

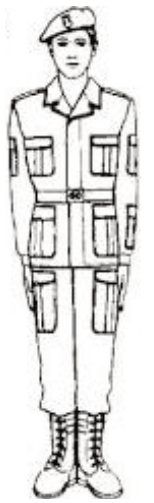

Fig. 5. The trunk-integrated erect human posture (i.e. where both hands are closely attached to the rest of the body. (Source: www.google.com/ search?q $=$ postawa + w + na + baczność $)$.

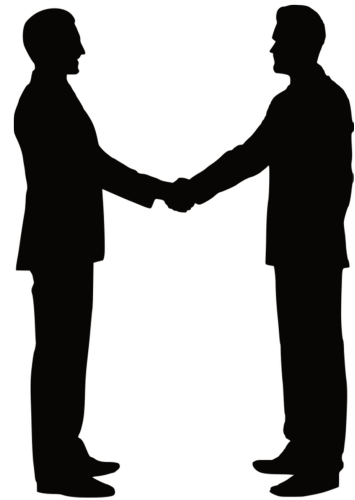

Fig. 6. The handshake in the context of the entire human body as an example of the right handprotruding operation during which the perimeter of the human body is not only frontally enlarged, but where the communicators maintain eye contact, i.e. where they see each other face-to-face. (Source: https://pixabay.com/vectors/silhouetteteam-building-3265909).

In protruding the hands frontally, as is the case with the protrusion of the right hand in the gesture of the handshake, the trunk of the human body becomes enlarged (extended) and somehow divided into two parts, the upper and the lower ones. Obviously, the upper part with the protruded right hand, being under more direct ocular control, is better monitored by the sense of sight. At the same time, the complex of the upper section of the trunk together with the extended right hand becomes loaded semantically and thus becomes biased culturally (see Fig. 6 below). This means that a particular culture has developed and attaches appropriate meaning(s) to this particular manual operation within what takes place within the bounds of what may be called the 'handshake architecture'. In the case of the Western culture, where the handshake gesture has been established as a ritual (cf. Bell, 1992; Bell, 1997; Schirch, 2005; Puppel, 2014) very early on (as is shown in the Figures 1-3 above), its semantic significance lies in 'building' a set of positive attitudes to the other person while being in direct face-to-face contact. We may state that the handshake is, generally, a 'peacebuilding-and-friendship-building gesture' (cf. Roodenburg, 1991; Schirch, 2005) and thus a great contributor to making peace and carrying out acts of mediation (cf. Curle, 1971). 


\section{The handshake as an empathic (peace-and-friendship-building) gesture}

In a non-conflicting culture with public space being managed emphatically, that is, the one which is based on peace-and-friendship-building gestures, the handshake occupies a central position in the human symbolic capital, owing to its manual straightforwardness and interpersonal communicative power (cf. Puppel and Puppel; Puppel, 2013) which are decisive. In answering the question: "what does the handshake communicate?" one may indicate the following:

- it is a strong sign of human sociality, that is, the handshake sheds a unique signal of interactivity into the public environment. In this way, it belongs to what has been referred to as the human 'interaction engine' (cf. Levinson and Enfield, 2006),

- it is a strong human-human approach behaviour (cf. Dolcos et al., 2012; Corr, 2013): that is, when two individuals are approaching each other to build a relation and where no threat is expected on both sides. It is naturally opposed to 'avoidance behaviour',

- it is an expression of both self-protection and trust in the other person as a physical being: that is, it charges the interpersonal space positively and signifies the removal of enmity and war-like tensions by demonstrating the 'I have no weapon' attitude,

- by assuming a non-violent attitude and disarming the hands (cf. Pinker, 2011) it is used by the human communicators to open up an agenda, that is, it opens up a common ground for a peaceful exchange of information and for making a familiar space which involves the handshake as a strong signal sent to the other human being(s) as regards the readiness both to cooperate and receive reciprocity (cf. Fang-Jing Wu eta 1., 2011),

- it serves to signal social inclusion,

- it serves to seal peace and reconciliation.

\section{Conclusions}

It follows from what has been stated above that the handshake has always been an extremely important gesture in human culture. Its uniqueness, power and significance lies especially in its positive binding potential. Its social usefulness seems to surpass other manual manipulations and gestures, for it directly serves to remove tensions between/among the human individuals that may accrue not only within one culture but also across cultures. The empathic (peace-and-friendship-building) value of the handshake, therefore, ought to be cherished as a central element of the human gestural interaction engine which humanity has finally arrived at in the course of its 
evolution and development. It is, therefore, postulated to be the kind of gesture which has acquired the status of a major human gesture, the leading 'anthropogesture', which is one of the pivotal gestures in building an empathic and peacebuilding culture.

\section{Bibliography}

Alpenfels, E.J. 1955. "The anthropology and social significance of the human hand". Artificial Limbs 2.2. 4-21.

Bell, C. 1992. Ritual theory, ritual practice. Oxford: Oxford University Press.

Bell, C. 1997. Ritual: perspectives and dimensions. Oxford: Oxford University Press.

Bergstrand, J. 2018. Arm motion and deformation of a real-time character. Luleå: Luleå University of Technology, Department of Arts and Education.

Brown, D.E. 1991. Human universals. New York: McGraw-Hill.

Cashmore, L., Uomini, N. and A. Chapelain. 2008. "The evolution of handedness in humans and great apes: a review and current issues". Journal of Anthropological Sciences 86. 7-35.

Cochel, H. and R.W. Byrne. 2013. "Evolutionary origins of human handedness: evaluating contrasting hypotheses". Animal Cognition 16.4. 531-542.

Corr, P.J. 2013. "Approach and avoidance behaviour: multiple systems and their interactions". Emotion Review 5.3. 285-290.

Curle, A. 1971. Making peace. London: Tavistock Publications.

Dolcos, S., K. Sung, Argo, J.J., Flor-Henry, S. and F. Dolcos. 2012. "The power of a handshake: neural correlates of evaluative judgments in observed social interactions". Journal of Cognitive Neuroscience 24.12. 2292-2305.

Edinger, J.A. and M.L. Patterson. 1983. "Nonverbal involvement and social control". Psychological Bulletin 93. 30-56.

Fang-Jing Wu, Feng-I Chu and Y-Chee Tseng. 2011. "Cyber-space handshake". SIGCOMM'11 (August, 15-10, Toronto, Canada).

Guirdham M. and O. Guirdham. 2017. Communicating across cultures at work. London: Palgrave.,

Hargie, O. and D. Dickson. 2004. Skilled interpersonal communication: research, theory and practice. London: Routledge.

Hewes, G.W. 1961. "Food transport and the origin of hominid bipedalism". American Anthropologist 63. 687-710.

Levinson, S.C. and N.J. Enfield. (eds.). 2006. Roots of human sociality: culture, cognition and interaction. Oxford: Berg Publishers.

Marzke, M.W. 1999. "Evolution of the hand and bipedality". In Lock, A. and C.R. Peters. (eds.). Handbook of human symbolic evolution. Oxford: Blackwell. 126-154.

Niemitz, C. 2010. "The evolution of the upright posture and gait - a review and a new synthesis". Naturwissenschaften 97.3. 241-263.

Pinker, S. 2011. The better angels of our nature: why violence has declined. New York: Viking Press.

Puppel, J. 2013. "Facework and gestures: a preliminary analysis of the communicative power of human performative non-verbal practices". Scripta Neophilologica Posnaniensia XIII. 85-90.

Puppel, J. 2014. Obecność i rola gestów rytualnych w przestrzeni publicznej. Poznań: Wydawnictwo Naukowe UAM.

Puppel, S. and J. Puppel. "Gestosfera jako istotny składnik komunikacyjnej przestrzeni publicznej: wstępny zarys problematyki". Oikeios Logos 4. 1-8. 
Rolian, C., D.E. Lieberman and B. Hallgrimsson. 2010. "The coevolution of human hands and feet". Evolution 64.6. 1558-1568.

Roodenburg, H. 1991. "The 'hand of friendship': shaking hands and other gestures in the Dutch Republic". In: Bremmer, J.N. and H. Roodenburg (eds.). A cultural history of gesture. Groningen: University of Groningen (s.n.). 152-189.

Schirch, L. 2005. Ritual and symbol in peacebuilding. Bloomfield, CT: Kumarian Press.

Synnott, A. 1993. The body social: symbolism, self and society. London: Routledge.

Turner, B.S. 1984/2008. The body in society: explorations in social theory. Oxford: Basil Blackwell.

Wilson, F.R. 1998. The hand: how its use shapes the brain, language, and human culture. New York: Pantheon Books. 